\title{
Growing health partnerships in rural and remote communities: what drives the joint efforts of primary schools and universities in maintaining service learning partnerships?
}

\author{
Sue Kirby ${ }^{1}$, Fabian P. Held ${ }^{2}$, Debra Jones ${ }^{3}$ and David Lyle ${ }^{4}$ \\ ${ }^{1}$ Senior Research Fellow, Broken Hill University Department of Rural Health, The University of Sydney, Broken Hill, \\ NSW, Australia \\ ${ }^{2}$ Charles Perkins Centre, Faculty of Science, School of Mathematics and Statistics, The University of Sydney, Broken \\ Hill, NSW, Australia \\ ${ }^{3}$ Director, Primary Health Care Stream, Broken Hill University Department of Rural Health, The University of Sydney, \\ Broken Hill, NSW, Australia \\ ${ }^{4}$ Head of Department, Broken Hill University Department of Rural Health, The University of Sydney, Broken Hill, \\ NSW, Australia
}

\begin{abstract}
Aim: This study explored the partnership between universities and local primary schools to deliver a classroom-based paediatric communication impairment service provided by undergraduate speech pathology students. It aimed to understand how partnerships work to facilitate programme replication. Background: The partners included universities sending students on rural clinical placement, local host academic units and primary schools who worked together to provide paediatric speech and language services in primary schools in three sites in Australia. Rural and remote communities experience poorer health outcomes because of chronic workforce shortages, social disadvantage and high Aboriginality, poor access to services and underfunding. Methods: The study was in twofold: qualitative analysis of data from interviews/focus group with the partners in the university and education sectors, and quantitative social network analysis of data from an electronic survey of the partners. Findings: Factors supporting partnerships were long-term, work and social relationships, commitment to community, trust and an appetite for risk-taking. We postulate that these characteristics are more likely to exist in rural communities.
\end{abstract}

Key words: community partnerships; qualitative research; rural health services; social network analysis; speech language pathology

Received 18 June 2017; revised 20 November 2017; accepted 26 November 2017; first published online 10 January 2018

\section{Background}

The strategy to provide rural undergraduate health professional clinical placements is used in countries where there are rural health workforce shortages. It is based on evidence that students who experience rural placements during their undergraduate years are more likely to take up rural practice after graduation

Correspondence to: Sue Kirby, PhD, The University of Sydney, Broken Hill, NSW 2880, Australia. Email: s.kirby@unsw.edu.au
(Lyle et al., 2006). In traditional placements, the student shadows the supervising clinician thereby learning how to provide appropriate care or service. Service learning is an alternate type of clinical placement in which undergraduate students provide services under supervision, usually in disadvantaged communities with high levels of unmet need (Clinical Education Australia, 2017). Service learning was developed in the 1990s in the United States to fulfil a major goal of the university sector to engage with their local communities (Seifer, 1998). Service 
learning is underpinned by the concept that students develop a sense of civic responsibility through their engagement in real world contexts (Jacoby, 1999; Lyle et al., 2006; Stahl et al., 2006). There is some evidence that student learning is enhanced in service learning compared with traditional placements (Warren, 2012; Briffa and Porter, 2013). Although Australian universities espouse community engagement, service learning has not been taken up to the same degree as in the United States (Jones et al., 2015). However, the rural service learning model which is the subject of this study has been examined to elucidate the factors which contribute to the student learning and work readiness (Jones et al., 2015).

In rural and remote Australian communities, reduced resources, access to services, availability of health professionals, lower health status, lower socioeconomic status, distance and travel translate to poorer health outcomes compared with metropolitan Australians (Standing Council on Health, 2012).

The programme under study provides paediatric screening, assessment and therapy for children with (speech and language) communication deficits. It is important to identify and treat communication delays in young children as they are associated with poor educational and social outcomes. After controlling for child characteristics, the impact of deficits in early speech and language development on literacy and numeracy were similar in magnitude to the effect of family socioeconomic factors (Australian Early Developmental Index, 2017).

This study explored partnerships between academic institutions and communities to support service learning programmes in Australia. It examined the development of school-based paediatric speech pathology (SP) service learning programme from the index site, Broken Hill in Far West New South Wales and compared the partnerships across two additional rural/remote sites which adopted the model - Geraldton (Western Australia) and Katherine (Northern Territory). The study explored factors which enabled and sustained an intersectoral service learning programme between the universities and the schools to inform the transferability service learning programmes to other locations with similar unmet need.

\section{Theoretical framework for the study}

Service learning is an intersectoral programme between universities and community-based agencies, in this instance local schools, working together to enable the delivery of student-assisted services to community members. Intersectoral programmes are an enduring feature of the provision of equitable health enhancing strategies to address complex problems in communities as articulated in the Ottawa Charter (Stahl et al., 2006; Commission for Social Determinants of Health, 2008; World Health Organisation, 2008).

Working across sectors demands a specific set of skills: understanding differences in interorganizational cultures, strategic aims, resource constraints and structures and processes. Partners need to ensure that the aims and objectives of the programme are being met and are consistent with those of the participating organizations (Bosma et al., 2010; Northmore and Hart, 2011). The term 'partnership' is defined as two or more organisations that ... 'make a commitment to work together on something that concerns both, to develop a shared sense of purpose and agenda, and to generate joint action towards agreed targets' (Stern and Green, 2005).

Partners in service learning programmes were reported as having commitment, credibility, consistency and adaptability (Jones et al., 2015). Understanding context is important in exploring cross-sectoral programmes (Halliday et al., 2004; Jones et al., 2015). A conceptual framework is also important in understanding cross-sectoral programmes (Polivka et al., 2001; Dowling et al., 2004; Casey, 2008; Johns, 2010). We adopted an evidence-based framework, the Continuum of Joint Effort (COJE) developed as a result of surveying partners working in Victoria, Australia in cross-sectoral programmes involving health services (Victorian Council of Social Services, 2009; VIC Health, 2011). The COJE incorporates a graduated scale from loose networks to partnerships to facilitate the exploration of the effectiveness of cross-sectoral programmes. Partnership status, attained when the cross-sectoral programme has fulfilled a set of criteria described in the COJE, is indicative of a robust working arrangement between the participating services in the cross-sectoral program. Dimensions of the COJE and their expression at different stages of joint efforts are described in Table 1.

\section{Research context}

We investigated intersectoral initiatives that support and maintain service learning programme 
Table 1 Continuum of joint effort

\begin{tabular}{|c|c|}
\hline $\begin{array}{l}\text { ASPECT OF } \\
\text { FUNCTIONING }\end{array}$ & $\begin{array}{l}\text { RELATIONSHIP DEVELOPMENT } \\
\text { FROM NETWORKING THROUGH } \\
\text { COOPERATION, COORDINATION, } \\
\text { COLLABORATION TO PARTNERSHIP }\end{array}$ \\
\hline TRUST & $\begin{array}{l}\text { Building from low to high trust } \\
\text { within the relationship }\end{array}$ \\
\hline LEVEL OF RISK & $\begin{array}{l}\text { Building from low level of risk taking } \\
\text { to high risk strategies }\end{array}$ \\
\hline $\begin{array}{l}\text { COMMITMENT OF } \\
\text { RESOURCES }\end{array}$ & $\begin{array}{l}\text { Building from minimal through } \\
\text { desire to commit and investment } \\
\text { resources committed and shared }\end{array}$ \\
\hline $\begin{array}{l}\text { REASON FOR } \\
\text { JOINING }\end{array}$ & $\begin{array}{l}\text { Building from previous joint projects } \\
\text { through projects to address unmet } \\
\text { need to shared vision and goals } \\
\text { defined in formal agreements }\end{array}$ \\
\hline $\begin{array}{l}\text { STRUCTURES AND } \\
\text { PROCESSES }\end{array}$ & $\begin{array}{l}\text { Building from nil to structures and } \\
\text { processes in place }\end{array}$ \\
\hline TIME FRAME & $\begin{array}{l}\text { Building from short to long term } \\
\text { sustainable }\end{array}$ \\
\hline $\begin{array}{l}\text { REGULAR } \\
\text { PLANNING }\end{array}$ & $\begin{array}{l}\text { Building from nil to regular planning } \\
\text { in place }\end{array}$ \\
\hline $\begin{array}{l}\text { STAKEHOLDER } \\
\text { FEEDBACK }\end{array}$ & $\begin{array}{l}\text { Building from nil to feedback } \\
\text { mechanisms in place }\end{array}$ \\
\hline
\end{tabular}

for SP students to provide speech and language screening, assessment and therapy to year one primary school pupils. A cohort of SP students worked in schools each term to provide a rolling programme, tracking pupil progress for a year and handing over to the next cohort. The service learning programme spans three sectors: primary school education, tertiary undergraduate education and health. The service learning programme, operating in high need rural areas lacking paediatric SP for primary school children, is depicted in Figure 1. The inception and development of the service learning programme in rural and remote New South Wales Australia has been described elsewhere (Jones et al., 2015).

The three sites included in this study were: (1) Broken Hill an outer regional population center of 18800 in Far West New South Wales; (2) Geraldton a coastal city in the Mid-Western region of Western Australia with a population of about 41200 and (3) Katherine in the Northern Territory with 11100 inhabitants (2016). The regions are socioeconomically disadvantaged with a poor health outcomes amplified across indigenous communities in each region (Kennedy, 2005; McGrail and Humphreys, 2009; National Rural
Health Alliance, 2013). The health workforce includes fly-in-fly-out workers and struggles with retention of health professionals, resulting in fragmented and incomplete care.

In Broken Hill, the service learning programme was instigated in 2008 (Jones et al., 2011; Victorian Council of Social Services, 2014). Comparator sites at Katherine and Geraldton started to develop their service learning programmes based the Broken Hill model in 2012. The assumption was that the service learning programmes in these sites would be less well developed because they had started later and had less time to build from network to partnership status as specified in the COJE conceptual framework.

\section{Methods}

\section{Design}

The study design was parallel convergent combining data analysis from qualitative interviews and quantitative social network surveys (Creswell and Plano Clark, 2011). Participants in the three sites were offered interviews or focus groups and invited to complete an online-survey. The qualitative and quantitative data sets were analysed independently, to avoid influence and contamination, and results from both strands merged to facilitate interpretation. The convergent design aimed to create synergistic interpretation of the findings which went beyond a sum of the two parts to better address the research question of how cross-sectoral service learning programmes work.

\section{Data collection}

The service learning programme stakeholders were identified by the local host university. Invitations were emailed to prospective participants: SP academics from source universities; host site service learning programme support staff involved in placement support; host site academics; host site school principals and teaching staff; local site and State/Territory Education officials. Clinical speech pathologists from participating health services engaged as supervisors or referral services were included in the sample. SP students were not included in the sample because the relatively short six- to eight-week placement duration made them a transient presence in the partnership. Parents 


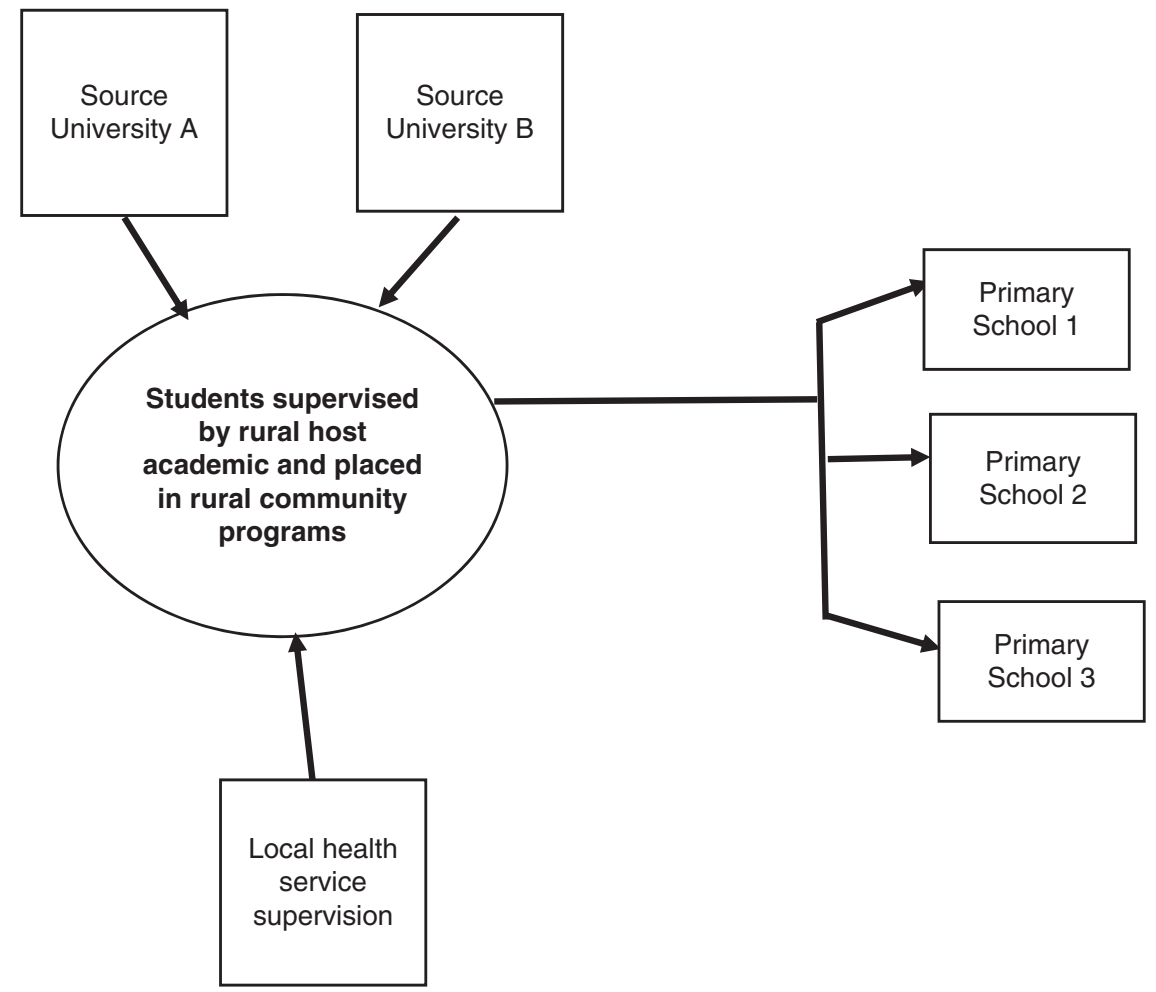

Figure 1 The cross-sector service learning partnership spanning three sectors; tertiary education; primary school education and health

were excluded from the sample because their role, although important, is peripheral in sustaining the service learning program.

Stakeholders were invited by email to participate by interview or focus group, whichever was convenient for them. Participants were offered telephone interviews/focus groups if face-to-face was inconvenient. Interviews/focus groups were conducted on site at the host university, in the schools or in an appropriate venue suitable to the participant(s) and took approximately $1 \mathrm{~h}$. Semi-structured interviews and focus groups were conducted during site visits by S.K. Stakeholders were asked to reflect on their experience of the service learning programme, their role in it, the factors which support its effective operation, problems encountered, how it could be changed (VIC Health, 2011).

In the week after each site visit, participants were invited to complete an online survey exploring the strength and depth of the interactions within the partnership. We adapted the social network name generator frequently used in the
General Social Survey (Davis et al., 2007). Each respondent was shown a list of the stakeholders from the interviews/focus groups, with the explanation that these were people involved in the partnership and asked to identify the range of interactions with them. These included: How often they interacted on average, what share of their interactions related to the service learning programme, and how they would describe the nature of their relation with options of 'family', 'work', 'friends' or 'social' (eg, hobbies, sport, religion, etc.). Respondents were also asked to specify their age (in categories 'up to 30', $31-40$ ', '41-50', '51-60','over 60'), gender, and in open-ended questions their occupation, and length of involvement in, as well as their role in the service learning program. The survey is shown at Figure 2.

Participation in the study was voluntary. Ethics approval was obtained from the Human Research Ethics Committees or equivalent from participating universities, State and Territory education departments and participating health services. 
Dear [First Name]

Thank you for participating in our survey. It should not take longer than $10 \mathrm{~min}$.

This survey is part of a multi-site study aiming to explore the partnership between the primary school communities and the universities that are necessary to initiate and maintain allied health service-learning programs.

Factors identified as important in community partnerships include engagement, shared decision making, and partnership structure. We need to understand how partnerships work to help set up health partnerships with effective procedures and structures to ensure better outcomes.

This survey focuses on the structure of social networks and relationships between people involved in the community-campus partnership in Katherine. Please help us understand how this partnership works by answering the following questions.

Should you have any further questions, please contact Dr Fabian Held,fabian.held@sydney.edu.au.

Demographics

Age

Gender

Occupation

Please indicate your length of involvement with service-learning [choices from less than one year to more than ten years]

Briefly describe your role in the partnership [Open text field]

On the next pages we will ask you about your relations to people that we identified as being important to the community-academic partnership around service-learning in Katherine. You may not even know all of these people. However for those that you know and interact with, please think of the whole range of interactions that you have with them when answering the following questions.

Please indicate by ticking the box those people with whom you interact from the list below.

List of all names

Please select for the following people how often you interact with them on average.

[choices from "once per month, or less", over "once per week" to "every day"]

List only names selected above

Please tell us by ticking the appropriate boxes about the nature of you relationship with these people? Select all that apply:

[options are Family, Work, Friends, Social (e.g. hobbies, sport, religion, etc.)]

List only names selected above

How strongly do you rate your influence on each of these people's behaviour, goals, decision-making or planning? Please indicate by positioning the slider.

- Strong (e.g. you are in a position to instruct this person and determine their actions)

- Medium (e.g. this person would consider your advice)

- Weak (e.g. you would be unlikely to have any effect)

[Slider from "weak" - "medium" - "strong"]

List only names selected above

What share of your interactions with each of these people relates to the community-campus partnership? Please indicate by positioning the slider. [Slider from None, over $50 \%$, to All]

List only names selected above

\section{Figure 2 Email invitation to Participants and eSurvey}




\section{Qualitative analysis}

Electronically recorded interviews/focus groups were transcribed verbatim, sent to participants for member checking and uploaded into Nvivo (http:// www.qsrinternational.com/) for analysis. S.K. read transcripts repeatedly to gain familiarity with the range of experiences and the relationships reported. Deductive thematic analysis was then conducted, informed by the factors identified in the COJE (Victorian Department of Human Services, 2009). Interpretation of the data was facilitated by linking emerging themes from the analysis to the following factors from the COJE: trust and risk, commitment of resources, trigger/purpose, time frame, structures and processes, feedback and planning.

\section{Social network analysis}

Data from the online survey, undertaken by F.H., provided an insight into the structure of interactions amongst service learning programme stakeholders. Based on their descriptions of occupation and role, we grouped them into three different areas to reflect their activity in the programme (University Sector Host, Host Placement, University Sector Source). Participant involvement was identified as 'strategic' or 'operational' capacity. The 'strategic' role, undertaken by more senior academics, involved dealing with policy and funding issues. The operational role, undertaken often by teachers and more junior academics, involved day-to-day operation of the programme and student supervision. Descriptive analysis summarized the demographics for each location individually, as well as for the entire sample.

To create a network, the reported relations were treated as undirected: an interaction is an activity involving both parties and, if at least one person in each pair indicated that there is a relation, we assumed that this relation exists between both of them. We used the minimum from two answers for frequency of interaction and share of interaction relating to the service learning program. The nature of the relation was defined as friend, family, social or work if indicated by at least one of the partners.

Inductive statistical models were applied to quantify and test how the observed network structure could be attributed to individuals' activity and other relational processes. These types of models are referred to as exponential random graph models (ERGMs). ERGMs, like logistic regression models, predict the existence or absence of a tie between each pair of respondents, depending on their individual attributes and their relations to others. ERGMs model the probability of tie formation as a dependent variable taking into account that observations are not independent in networks. To improve statistical power, all three networks were combined into one model, but the analysis was restricted to allow only relations within each community. The four classes of effects in the model were:

- Edges: similar to the intercept in other regression models, this effect is included to represent the overall number of relations observed in a network. A negative coefficient indicates that $<50 \%$ of all potential ties are observed.

- Activity: quantifies if members with a certain attribute tend to have more or fewer ties.

- Mixing: captures the effect of attribute combinations between two partners.

- Other relations: assesses if a tie becomes more, or less likely if another type of relation exists between the potential partners.

ERGMs allowed us to test if these processes led to significantly more (or fewer) ties than would be expected by chance, in a randomly connected network made up of the same people. To do this ERGMs provide inference statistical tests to assess if these effects are significantly different from zero (Robins et al., 2007; Morris et al., 2008). Analogous coefficients in logistic regression models, the resulting ERGM coefficients are interpreted as additive factors on the log odds of forming a learning relationship. Significant and positive coefficients indicate higher log odds of forming a relation in accordance to the underlying process; negative coefficients make it less likely. In the tabular output, significant coefficients are highlighted with asterisks. The goodness of fit of each of these models was assessed, following the procedures in Hunter et al. (2008), ensuring that the proposed models reproduce a series of endogenous network features. Analyses were conducted in $\mathrm{R}$ version 3.3.0 ( $\mathrm{R}$ Core Development Team, 2014), using the statnet suite of packages (Handcock et al., 2008). 
Our analysis aimed to explain the network which sustained the service learning programme. Therefore, relations between respondents where $<5 \%$ of interactions related to the service learning programme were dismissed. Work relations were deemed independent of the service learning programme if they had fewer than $80 \%$ of interactions relating to the service learning program. These were used as independent relation in the modelling. Ties related to the service learning programme were considered as missing if none of the two partners responded to our online survey. For non-respondents, we imputed attributes of age and length of involvement with the median.

\section{Results}

Two prospective participants from source universities declined because of lack of current involvement in the service learning program. Four community schools participated in Broken Hill, three in Geraldton and six in Katherine. Of the 49 invited to participate in the survey after interviews/ focus groups, 39 responded. Participant details are presented in Table 2.

\section{Qualitative results}

Emergent themes from the qualitative analysis were aligned with the categories of the COJE to understand the features of the service learning programmes.

\section{Trust and risk}

Trust between partners was consistently reported as an important partnership ingredient developed over time as partners had worked in other joint projects predating the service learning program. However, high levels of trust were reportedly associated with high levels of risk in the relationships. All stakeholders reported close personal relationships within the service learning programme strengthened by social interactions within local communities. The combination of work and social networking was considered to enrich the level of interaction and facilitate working together.

'I think it's got a lot to do with the culture.... We do things differently out here, apparently, as a collective of principals and schools. And to me, if it benefits one kid, it's worth buying in to'.

(Academic Host University, Broken Hill)

Table 2 Participant details

\begin{tabular}{|c|c|c|c|c|c|c|c|}
\hline \multirow[t]{3}{*}{ Sector } & \multirow[t]{3}{*}{ Role and level } & \multicolumn{6}{|c|}{ Number of participants (number of refusals) } \\
\hline & & \multicolumn{3}{|c|}{ Interview/focus group } & \multicolumn{3}{|c|}{ Survey } \\
\hline & & $\begin{array}{l}\text { Broken } \\
\text { Hill }\end{array}$ & Geraldton & Katherine & $\begin{array}{l}\text { Broken } \\
\text { Hill }\end{array}$ & Geraldton & Katherine \\
\hline \multirow[t]{5}{*}{ Host Placements } & Teachers (operational) & 7 & 3 & 6 & 7 & $2(1)$ & $4(2)$ \\
\hline & Principals (strategic) & 2 & 3 & 3 & 2 & 3 & $1(2)$ \\
\hline & Community partners (strategic) & & $2^{a}$ & 1 & & $1^{a}(1)$ & 1 \\
\hline & $\begin{array}{l}\text { State education department } \\
\text { partner (strategic) }\end{array}$ & 1 & & & 1 & & \\
\hline & $\begin{array}{l}\text { Public health service provider } \\
\text { (operational) }\end{array}$ & 3 & $1 \mathrm{a}$ & 1 & $2(1)$ & $1^{a}$ & 1 \\
\hline \multirow[t]{3}{*}{$\begin{array}{l}\text { University Sector } \\
\text { Host }\end{array}$} & $\begin{array}{l}\text { Speech pathology academic } \\
\text { (operational }^{\text {b }} \text { ) }\end{array}$ & 1 & 1 & 2 & 1 & 1 & $1(1)$ \\
\hline & Senior academic (strategic) & 2 & 2 & 1 & 2 & $1(1)$ & 1 \\
\hline & Admin team (operational) & 2 & 3 & 1 & 2 & 3 & $(1)$ \\
\hline \multirow[t]{2}{*}{$\begin{array}{l}\text { University Sector } \\
\text { Source }\end{array}$} & $\begin{array}{l}\text { Speech pathology academic } \\
\text { (operational) }\end{array}$ & $0(1)$ & $1(1)$ & 1 & & 1 & 1 \\
\hline & Total & 18 & 15 & 16 & 17 & 12 & 10 \\
\hline
\end{tabular}

Numbers in brackets indicate the number of potential participants who did not participate.

a One participant had a dual role as a community member and a health service provider.

${ }^{b}$ Although the main role of the speech pathology academics is day-to-day problem solving and liaison, they do play a strategic role as well. 
'You don't have layer upon layer of, the numbers are small enough that you know people, that you run into them'.

(Academic Host University, Broken Hill)

'... and the underpinning feature is the relationship - we're strong. And that's where the strengths, I think, of those relationships .... and the trust has been as well'.

(School Principal, Broken Hill)

Stakeholders in both schools and local universities consistently reported a long working relationship allowing for the development of trust on both sides. The relationship between local and source universities was similarly matured, with a high level of trust.

Partners agreed that relationships required ongoing monitoring to assess success of the service learning programme and troubleshoot when things went wrong. Troubleshooting was undertaken by the local academics responsible for day-to-day operation. More senior academics were involved in policy development.

\section{Investment of resources committed and shared}

All stakeholders reported sharing of resources to maintain the service learning programme in the absence of government funding. The operation of the service learning programme fell on the local host university to arrange and support student placements and on the schools to provide the host setting. Stakeholders reported that the investment of their resources was necessary to provide paediatric communication services, which would otherwise not be provided: it was a struggle to find resources to continue the service learning program, but it was a high priority. Resources contributed to maintain the service learning programmes were: (1) clinical academic units in host universities - student supervision and school and source university liaison; (2) schools service venue/clients, liaison with the host university and (3) source/feeder university - student supervision.

Senior academic stakeholders reported that the most serious risk to the partnerships at all sites was a failure to embed the service learning programme into government health and education policy thereby securing funding. At the federal level, the now defunct Health Workforce Australia supported the service learning programme as a model for enhanced learning and rural experience for undergraduate students (Health Workforce Australia, 2013). The Broken Hill programme had in-kind support of the New South Wales State Department of Education, and has recently received some funding to support the SP academic position. The Western Australian and Northern Territory Departments of Education had not provided financial or policy support for the program. The lack of government funding translated to an insecure future for the programmes. Partners reported that the host academic organizations continued to deliver the programme although the cost was considerably higher than the traditional apprenticeship model (shadowing) clinical placement (Clincal Education Australia, 2017). Reasons for this included the high cost of local student supervision/support and the necessity to maintain regular high trust relationship with the schools and source universities. Additional funding allocated to University Departments of Rural Health in the 2015-16 budget may ease funding burden on the service learning programme (Department of Health, 2016).

'Can we go back to the funding actually ... because I think sometimes people use it as an excuse and it's correlated to what I've said before, a lot of that project, in Katherine anyway, is supported by goodwill and in-kind'.

(Senior Academic, Katherine)

'...so it's sort of like this is my town, I care about what happens to it. So sometimes you have to juggle, am I talking from a point of view being a community member or am I talking as a site manager?'

(Community Service Provider, Katherine)

An innovation adopted in two sites was conjointly funded local health service/university positions.

'one of the things we would have loved to have got more of is jointly funded placements where we have an academic position here and a clinical appointment in the hospital or in the health service somehow'.

(Senior Academic, Geraldton) 
'Look I will say that our model is very, very complex to deal with, and what we try to do is have a very relaxed conversation with our university partners, and we're like a swan floating on the water, and our little legs are just going 100 miles an hour underneath'.

(Senior Academic Host University, Geraldton)

\section{Trigger, purpose, vision and goals defined in MoUs formal agreements}

Stakeholders reported that the triggers for the programme in all three communities were unmet demand for services and a commitment to help their communities. In the comparator sites a secondary trigger operated: key academics heard about the index site model development in Broken Hill and arranged discussion and site observation leading to establishment of their own program. Broken Hill academics provided set up support at the comparator sites and continue to support and discuss the development of the service learning programme thereby maintaining a support network across the three sites. The purpose, vision and goals for the programmes were predicated by the unmet need for paediatric communication services.

'They [primary school principals] had a much stronger history around the frustrations around accessing speech for our kids...'.

(School Principal, Broken Hill)

'Of course, because when children aren't learning well they get frustrated and they get behavioural issues'

(Community Service Provider, Katherine)

Stakeholders across the three sites reported long-term relationships between the local university and the schools within their communities had facilitated working together on the service learning program.

'Because both [name] and I have been here for 32 and 25 years, we have got long-term relationships within the health sector and the wider sector, because of the range of positions that we've done in our time. So after [our visit tol Broken Hill we had certainly done our own internalised thinking about what were the opportunities, and started to talk with various stakeholders around the town. So, this meeting at the symposium was really - well let's come together, let's bring these groups together to hear the same story, and hear the journey that another organisation has made and where they've got to four and five years down the track'.

(Senior Academic, Geraldton)

\section{Structures/processes in participating organizations at operational and strategic levels}

The structures and processes identified as important hinged on role delineation. The most important role for day-to-day service learning programme operation was that of the local academic supervisor who acted as a troubleshooter and key channel of communication between students, host and source universities and schools. This role was consistent across the three sites. Another key role was that of strategic leadership which fell to a senior academic at the local host university and involved negotiation to maintain the flow of students from source universities and lobbying for government policy change and funding.

'... certainly [name - senior academic] has been the guy who's really pushed the service learning, and I think it is a model that we've all felt we like the concept of'.

(Senior Academic, Geraldton)

Support for students on placement was a costly component of the service learning program. Common problems were: poor pre-placement preparation and lack of maturity, cultural understanding, ability to self-manage and ability to meet learning goals. Problems were resolved by negotiation between the local host academic, the source university and the school. Source university problems arose in relation to the timing and length of student placements as prescribed by the service learning programme to fit in with the rest of the university curriculum.

Formal agreements, memorandum of understanding (MoU) and bilateral agreement letters, were used to underpin the partnership in the comparator sites, but not in the index site. 
There was one instance reported in a comparator site when a school was unhappy with the operation of the service learning programme but decided not to invoke the formal agreement and resolved difficulties through negotiation.

'Last year was tricky. We probably need to revisit the MOU again - that was done in the beginning of 2014 we had and that's not revisited on a normal basis, so'.

\section{(School Principal, Geraldton)}

Other structures and processes were less formal. Across the three sites, the service learning programme was maintained by regular contact which hinged around the roles of the academics at the host university.

\section{Regular planning and feedback to stakeholders}

Programme planning and feedback was accomplished through meetings of those involved in the service learning program.

'We have a network called [name] with a member ship of about 186 people here in town.... It meets bimonthly and we look at what's happening in the community...'.

(Community Service Provider, Katherine)

The growth in undergraduate courses in Australia has led to increasing competition for placements amongst source/feeder universities. Improved take up of the service learning programme could result in more services for schools, more placements for students, more students per student cohort and longer placements to coincide with school terms, all desirable outcomes.

'Also, I mean, it would be worth noting that there are only increasing number of speech pathology course in Australia, and they're growing, placements are hard to get'.

(Academic Host University, Broken Hill)

School problems related to access to clinic space for the service learning programme in the school, arrangements for withdrawing school pupils from class for individual or small group work and new teachers settling into the program. These were resolved through negotiation between the school and the host academic. Operational problems were resolved through negotiation and shared decision making and did not involve the strategic level of the partnership. Stakeholders reported that student learning was enhanced by service learning placements.

'We had a 15 to 20-minute conversation for the term four preplacement last year where the two teachers negotiated how they were going to move all these other events to accommodate the students, which was sort of heart-warming at the time and it would have been much easier to say we can't do it. But instead they worked hard to find a window of opportunity for their kids to get that service'.

(Academic Host University, Broken Hill)

'It's (the service learning program) not too much of an imposition on the class. They come in and they take one of the students at a time to do the assessments. Sometimes the girls would say that they would love all the kids to just be assessed, obviously, that's a time frame. So, you could have more students come I would suppose and that would be something you could change I suppose'.

(Teacher, Broken Hill)

'If that has been a poor relationship [SP student-school] then the next group will suffer. I'll have to sit down with the next [SP] students going to [school name] and have a bit of a chat to them about their thoughts on how they're going to develop a positive relationship with teachers in a short period of time'.

(Academic Host University, Broken Hill)

Teachers from all sites described examples of communication improvements in individual school pupils because of the service learning program, reported to them by parents and observed by them in the classroom. School learner impact was particularly noticeable manifested as gains in Australian English (the language spoken in primary schools) in Aboriginal children. In Geraldton and Katherine Aboriginal communities, Aboriginal language and Kriol were spoken at home with family and the community. Children had to learn to communicate in Australian English on commencing school.

'They [the pupils] from the time I've been here they seem to respond positively. They, it gives 
them a chance to see outsiders and gets them a little bit extra help too ... So, they [students] just come in sit with the kid and listen to them read. That's valuable for us. The kids get more practice'.

(Teacher, Geraldton)

'I've witnessed slight improvement in their speech.... So, that was good in-home language, now can you tell me in school language? So, I make them - I repeat the sentence and stuff like that. I'm noticing ... I'm getting better behaviour as time goes on'.

(Principal, Geraldton)

\section{Social network analysis results}

Our sampling identified 49 service learning programme stakeholders in the three communities (18 in Broken Hill, 15 in Geraldton and 16 in Katherine). The characteristics of the 39 participants who responded to the survey are shown at Table 2.

The total number of relevant relations was 148, which is $19.6 \%$ of all 756 possible relations across these three networks. The networks of stakeholder relations for each of the three communities are depicted in Figure 2. Each network member is represented by an icon with shapes representing their affiliation and colour reflecting their level of operation regarding the service learning program.

To statistically test the effect of processes that lead to the observed networks, we configured ERGMs for the collection of all three networks. In an iterative process, we included an overall effect for the number of observed ties and then assessed the effects of various attributes on activity and mixing as well as the effects of other types of relations (independent work and social relations) (Harris, 2014). In the process, we removed several terms as they were not significant and had a negative effect on the model fit (as measured by BIC). Terms that were removed included activity effects of site, gender and operational role; mixing effects of age, gender, strategic and operational levels and roles in the service learning program, and effects of existing family ties. Results of the final model are summarized in Table 3.

The ERGM provided a detailed understanding into the social processes contributing to the observed service learning programme network.
As their coefficients were effects on the log odds, for ease of interpretation, the rightmost column in Table 4 shows the effect on the odds of forming a tie. Members of host universities are comparatively more active than other network members: ties with them are 6.5 times more likely than a random process would suggest. Similarly, the odds of observing a tie with strategic partners are 2.3 times higher, compared with someone who is not strategic. There was a non-significant, negative effect for ties with stakeholders that have started to engage with the service learning programme in the last 3.5 years. This effect was only retained in the model to control for the effect of mixing among stakeholders that have a similar length of involvement. It shows that is two times more likely a tie between partners who have been involved in the service learning programme for a similar amount of time (at a threshold of one year difference). There were no other significant effects regarding the mixing of attributes. We saw a substantial impact from the existence of other relations: if two network members had an existing friendship relation, they were 7.5 times more likely to show a relation that is also relevant to the service learning program. Similarly, their odds were increased by 5.3 if they indicated that they knew each other socially. Lastly, the most pronounced effect on observing a tie in the service learning programme network was attributed to an existing work relation where partners interact at least once a week on subject independent of the service learning program. These relations make it 35.1 times more likely to observe a relation that is relevant to the service learning programme as well.

\section{Discussion}

Analysis of the qualitative data demonstrated that community-campus partnerships supporting service learning programmes across the three sites were triggered and maintained by a commitment to providing services in areas of unmet need and a high level of trust between partners engendered by a history of working together on other programmes. In terms of the COJE (Victorian Council of Social Services, 2009; Victorian Healthcare Association, 2009; VIC Health, 2011), all the service learning programmes were at the high trust/ high risk end of the spectrum, and could be seen as 
514 Sue Kirby et al.

Table 3 Descriptive statistics to summarize demographics of respondents and networks, separately for each community and in total for our study

\begin{tabular}{lcccc}
\hline & Broken Hill & Geraldton & Katherine & Total \\
\hline Network & & & & \\
$\quad$ \#Members & 18 & 15 & 16 & 49 \\
$\quad$ Missing respondents & 1 & 3 & 6 & 10 \\
Attributes & & & & \\
$\quad$ Age (most frequent category) & $41-50$ & $41-50$ & $41-50$ & $41-50$ \\
Role: host university & 5 & 5 & 2 & 16 \\
Role: host placement & 12 & 6 & 7 & 31 \\
Role: source university & 0 & 1 & 1 & 2 \\
Females/males & $13 / 4$ & $10 / 2$ & $9 / 1$ & $32 / 7$ \\
Strategic & 8 & 6 & 6 & 20 \\
Operational & 12 & 13 & 11 & 36 \\
$\quad$ Years of involvement (SD) & $4.7(2.8)$ & $5.1(2.3)$ & $4.6(2.3)$ & $4.8(2.4)$ \\
Relations & & & & 169 \\
Ties reported & 74 & 49 & 46 & 148 \\
Ties relevant to SLP & 66 & 41 & 41 & 66 \\
Friends & 20 & 41 & 5 & 24 \\
Social & 20 & 4 & 0 & 2 \\
Family & 2 & 0 & 0 & \\
\hline
\end{tabular}

$\mathrm{SLP}=$ service learning program

Table 4 Results from exponential random graph model estimation

\begin{tabular}{lrlll}
\hline & Estimate & Std. Error & $p$-value & Effect on Odds \\
\hline Intercept & -3.41 & 0.43 & $0.000^{* * *}$ & 0.0 \\
Activity & 1.86 & 0.32 & $0.000^{* * *}$ & 6.5 \\
$\quad$ Host University & 0.81 & 0.23 & $0.000^{* * *}$ & 2.3 \\
$\quad$ Strategic & -0.32 & 0.26 & 0.227 & 0.7 \\
$\quad$ More Recent Involvement (<3.5 Year) & & & & \\
Mixing & 0.69 & 0.33 & $0.037^{*}$ & 2.0 \\
$\quad$ Involvement similar to approx. 1 Year & & & $0.002^{* *}$ & 7.5 \\
Other Relations & 2.02 & 0.66 & $0.024^{*}$ & 5.3 \\
$\quad$ Friends & 1.67 & 0.74 & $0.000^{* * *}$ & 35.1 \\
$\quad$ Social & 3.56 & 0.44 & & \\
$\quad$ Frequent Other Joint Work & & & & \\
\hline
\end{tabular}

Four classes of process were modelled with regards to their effect on the likelihood of observing a tie in the combined network of three communities.

${ }^{*} p<0.05,{ }^{* *} p<0.01 ; * * 0<0.001$.

AIC: 303.1, BIC: 334.2

partnerships. This finding was contrary to our original assumption that the service learning programmes would be less well developed in terms of the progression to partnership in two comparator sites because the service learning programmes started later. This is confirmed by social network analysis (SNA), where the effects of site specific activity were not significant and have not been included in the final model. Other models have been applied to measuring the effectiveness of intersectoral collaborations (Polivka et al., 2001;
Casey, 2008; Johns, 2010). Application of the COJE is justifiable because it provided a good fit with the qualitative data. Local host site academics were the drivers who provided the leadership role for the service learning program. Others have reported that leadership to inspire trust was important in the development of rural Australian intersectoral collaborations (Tubin and LevinRozalis, 2008; Walker et al., 2009; Johns, 2010). Failure to embed the service learning placement model in government health and education policy 
is a threat to sustainability. The service learning programmes were characterized by a relatively informal governance approach. Bilateral MoU were used in the two remote sites, but there were no other formal governance structures. In spite of this, the programmes have operated successfully over a number of years, relying on day-to-day liaison and the trust developed between partners. Other researchers have reported that a minority of rural intersectoral collaboratives operate with formal agreements (Polivka et al., 2001).

SNA confirmed that drivers of the service learning programme were the academics in the host university: these roles were the most active in the network. Another finding of the interview/ focus group data, that long-term relationships built strong partnership, was also confirmed by SNA: work/social interactions occurring once a week or more often were a hallmark of strong ties. This reinforcing of work and social relationships in rural communities has been reported by others (Polivka et al., 2001; Johns, 2010).

Other findings from the SNA also point to the importance of trust: network members were more likely to interact with each other if they had other types of relations in common, including friendship, other social relations, as well as frequent, but independent interactions at work. We speculate, therefore, that the service learning programmes leveraged existing relations between members of the same community to build the collaborations that sustain the partnerships.

This is in part reflected by the positive mixing effect relating to the length of involvement in the partnership. Our stakeholders fell into two groups, relative newcomers to their local partnerships or people who have been involved for many years. For people with extended involvement, trust between them has built up over the years.

\section{Strengths and limitations}

Convergent parallel design provided a platform for the integration of qualitative and quantitative methods, reinforcing key findings and yielding a synergistic interpretation not be possible with two separate studies. Integration of the analyses highlights: the importance of the host university in initiating and maintaining the service learning program, both at the operational and strategic levels; the partnership-promoting impact of combined long-term work and social relationships and contextual issues such as funding and policy impacting on partnership formation and development. The study design is a strong feature of this research adding weight to the findings.

Limitations of the study include the single time point for data collection asking participants to recollect the partnership over a period of some years possibly leading to inaccuracies. Similar studies with other programmes at a range of other locations would help to clarify our findings. Other limitations are the lack of rigorous evidence on the impact of the service learning programme on school pupil communication outcomes and on undergraduate student learning. Both are areas for future research.

The findings illustrate a platform for community health interventions: strong local partnerships facilitate the development of local services to meet community needs (World Health Organisation, 1986). In this example, the service learning programmes across the three Australian rural and remote sites have operated 'below the radar' of government policy, without specific funding, but have improved outcomes for school starters and undergraduate students. There are resource implications in engaging in partnerships. 'Committing to the 'long haul' has its challenges but they are far outweighed by the benefits accrued by communities and partner organisations' (Jones et al., 2015).

Is this Australian study in rural and remote communities relevant to communities in general and to communities outside Australia? We believe it is. An important 'take-home message' for academic institutions wanting to adopt service learning is the value of local community relationships forged over many years, strengthened by work and social interactions between individuals with a desire to improve community outcomes. Our findings confirm that work/social interactions build trust and support risk taking. It may be that the reinforcement of work and social relationships between members of the partnership are more likely in smaller rural and remote communities. Rural and remote workers tend to stay in their jobs to stay in the community. This stability allows longer time periods for friendships and work relationships to flourish (Lyle et al., 2006). In addition, universitycommunity partnerships benefit marginalized communities by providing access to intellectual, social, economic and cultural resources in 
universities (Warr and Williams, 2016). Relationship building is also helped by the fact that in the rural and regional areas people live and socialize in the same area in which they work. Work-social reinforcement of relationships would be less likely to occur in regional and metropolitan areas where people tend to live and work in different locations. The relatively informal governance structures adopted may also be a product of rural/remote communities where people know and trust each other and may therefore place less emphasis on formal arrangements then urban and regional communities. The speculations about the impact of social relationships reinforcing work relationships in rural and remote communities should be tested by studies with direct comparisons of rural/remote and urban cross-sectoral programmes.

\section{Conclusion}

This study found that strong long-term partnerships had developed communities to support crosssectoral programmes. Partnerships are more likely to prosper in rural and remote communities where personal and social interactions overlap, because individuals in the partnership are more likely to trust their fellow workers in the partnership and more likely to take risks to maintain the partnership for the good of their community. It is a testament to the goodwill within these partnerships that they have continued despite lack of specific funding. Crosssectoral programmes in urban and regional areas are less likely to draw on the reinforcement between work and social relationships which feature in rural/ remote areas. The findings are a useful guide to those wishing to adopt cross-sectoral programmes in other locations.

\section{Acknowledgements}

The authors would like to acknowledge the participants who generously gave their time to take part in this study.

\section{References}

Australian Bureau of Statistics 2016: Regional population growth, Australia, 2014-15: population estimates by local government area (ASGS 2015), 2005 to 2015, Australian Bureau of Statistics.
Australian Early Developmental Index 2017: Australian Early Development Index, Retrieved 20 November 2017 from www.rch.org.au/aedi/.

Bosma, L.M., Sieving, R.E., Ericson, A., Russ, P., Cavender, L. and Bonine, M. 2010: Elements for successful collaboration between K-8 school, community agency, and university partners: the lead peace partnership. Journal of School Health 80, 501-7.

Briffa, C. and Porter, J. 2013: A systematic review of the collaborative clinical education model to inform speechlanguage pathology practice. International Journal of Speech-Language Pathology 15, 564-74.

Casey, M. 2008: Partnership - success factors of interorganizational relationships. Journal of Nursing Management $16,72-83$.

Clinical Education Australia 2017: Placement models and approaches to supervision. Retrieved 20 November 2017 from http://www.clinedaus.org.au/topics-category/placementmodels-and-approaches-to-supervision- 88 .

Commission for Social Determinants of Health 2008: Closing the gap in a generation: health equity through action on the social determinants of health. Final Report of the Commission on Social Determinants of Health. Geneva: WHO.

Creswell, J. and Plano Clark, V. 2011. Designing and conducting mixed methods research. Thousand Oaks, CA: Sage Publications Inc,.

Davis, J.A., Smith, T.W. and Marsden, P.V. 2007: General social surveys, 1972-2006: cumulative codebook. Chicago: Inter-university Consortium for Political and Social Research.

Department of Health 2016: Rural health multidisciplinary training (RHMT) 2016-2018 - Programme framework. Retrieved 7 December 2016 from http://www.health. gov.au/internet/main/publishing.nsf/Content/rural-healthmultidisciplinary-training-programme-framework.

Dowling, B., Powell, M. and Glendinning, C. 2004: Conceptualising successful partnerships. Health \& Social Care in the Community 12, 309-17.

Halliday, J, Asthana, S and Richardson, S 2004: Evaluating partnership: the role of formal assessment tools. Evaluation \& the Health Professions 10, 285-303.

Handcock, M.S., Hunter, D.R., Butts, C.T., Goodreau, S.M. and Morris, M. 2008: statnet: Software tools for the representation, visualization, analysis and simulation of network data. Journal of Statistical Software 24, 1548.

Harris, J. 2014. An introduction to exponential random graph modeling. Thousand Oaks, California: Quantitative Applications in the Social Sciences.

Health Workforce Australia 2013: National Rural and Remote Health Workforce Innovation and Reform Strategy.

Hunter, D.R., Goodreau, S.M. and Handcock, M.S. 2008: Goodness of fit of social network models. Journal of the American Statistical Association 103, 248-58.

Jacoby, B. 1999: Partnerships for service learning. New Directions for Student Services 1999, 19-35. 
Johns, S 2010: Early childhood service development and intersectoral collaboration in rural Australia. Australian Journal of Primary Health 16, 40-46.

Jones, D., Grant-Thomson, D., Bourne, E., Clark, P., Beck, H. and Lyle, D. 2011: Model for rural and remote speech pathology student placements: using non-traditional sites and partnerships. Australian Journal of Rural Health 19, 52-3.

Jones, D., McAllister, L., Riley, S., Lyle, D., Brunero, C. and Webb, T. 2015: Improving health and education outcomes for children in remote communities: a cross-sector and developmental evaluation approach. Gateways: International Journal of Community Research and Engagement 8, $1-22$.

Kennedy, C. 2005: Health in the Murdi Paaki, Broken Hill Centre for Remote Health Research, University Department of Rural Health.

Lyle, D., Morris, J., Garne, D., Jones, D., Pitt, M., Walker, T. and Weston, R. 2006: Value adding through regional coordination of rural placements for all health disciplines: The Broken Hill experience. Australian Journal of Rural Health 14, 244-48.

McGrail, M. and Humphreys, J. 2009: Geographical classifications to guide rural health policy in Australia. Australia and New Zealand Health Policy 6, 28-35.

Morris, M., Handcock, M. S. and Hunter, D. R. 2008: Specification of exponential-family random graph models: terms and computational aspects. Journal of Statistical Software 24, 1548-7660.

National Rural Health Alliance 2013: A snapshot of poverty in rural and regional Australia. National Rural Health Alliance. Deakin West, ACT, Australia.

Northmore, S and Hart, A. 2011: Sustaining communityuniversity partnerships. Gateways: International Journal of Community Research and Engagement 4, 1-11.

Polivka, B., Dresbach, S., Heimlich, J. and Elliott, M. 2001: Interagency relationships among rural early intervention collaboratives. Public Health Nursing 18, 340-49.

Robins, G., Pattison, P., Kalish, Y. and Lusher, D. 2007: An introduction to exponential random graph $\left(\mathrm{p}^{*}\right)$ models for social networks. Social Networks 29, 173-91.

R Core Development Team 2014: "R: A Language and Environment for Statistical Computing”, R Foundation for Statistical Computing, Vienna, Austria available at http:// www.R-project.org.

Seifer, SD. 1998: Service-learning: community-campus partnerships for health professions education. Academic Medicine 73, 273-77.

Stahl, T., Wismar, M., Ollila, E., Lahtinen, E. and Leppo, K. 2006: Health-in-all-policies: prospects and potentials: track 4 partnerships and intersectoral action. Retrieved 4 January 2018 from http:/www.who.int/healthpromotion/conferences/ $7 \mathrm{gchp} / \mathrm{track} 4 / \mathrm{en} /$.

Standing Council on Health. 2012: The National Strategic Framework for Rural and Remote Health, Australian Health Ministers' Advisory Council's Rural Health Standing Committee. Retrieved 9 June 2017 from http://www. health.gov.au/internet/main/publishing.nsf/Content/nationalstrategic-framework-rural-remote-health.

Stern, $\mathbf{R}$ and Green, J. 2005: Boundary workers and the management of frustration: a case study of two healthy city partnerships. Health Promotion International 20, 269-76.

Tubin, D and Levin-Rozalis, M. 2008: Interorganizational cooperation: the structural aspect of nurturing trust. International Journal of Public Sector Management 21, 704-22.

VIC Health 2011. The partnerships analysis tool. Melbourne: Victorian Health Promotion Foundation.

Victorian Council of Social Services 2009: Partnering in progress. Melbourne, VIC: VCOSS.

Victorian Council of Social Services 2014: Partnership practice guide. Guide 3: sustaining the partnership. Melbourne, Victoria, Australia: VCOSS.

Victorian Department of Human Services 2009: Partnering in progress. Retrieved 4 January 2018 from http://www.vcoss.org. au/documents/VCOSS \%20docs/HSPIC/Partnering \%20in \% 20Progress_Final_091029.pdf.

Victorian Healthcare Association 2009: Working in partnership. Retrieved 4 January 2018 from http://C:/Users/Sue/ Documents/EndNote\%20Master/Service\%20learning.Data/ PDF/3396620438/population-health-planning-framework_ partnersh.pdf.

Walker, R., Smith, P. and Adam, J. 2009: Making partnerships work: issues of risk, trust and control for managers and service providers. Health Care Analysis 17, 47-67.

Warr, D and Williams, R. 2016: Two steps forward, one step back: achievements and limitations of university-community partnerships in addressing neighbourhood socioeconomic disadvantage. Gateways: International Journal of Community Research and Engagement 9, 22-40.

Warren, JL. 2012: Does service-learning increase student learning? A meta-analysis. Michigan Journal of Community Service Learning 18, 56-61.

World Health Organisation 1986: The Ottawa Charter for health promotion. Retrieved 4 January 2018 from http://www. who.int/healthpromotion/conferences/previous/ottawa/en/ index $4 . h$ tml

World Health Organisation 2008: Primary health care: now more than ever. WHO World Health Report. 